\title{
I never asked to be ICE'd
}

A while ago I was talking with friends about the visit one of us recently had to make to her general practitioner.

"Don't you hate it when they ask you what you think is wrong?" she asked. "I was tempted to say, 'why, don't you know? You're the bloody doctor. If I knew what was wrong already I wouldn't need the GP!"

We'd all experienced something similar, and none of us could work out why our doctors were doing it.

\section{Being ICE'd}

One day I mentioned it to friend who is a GP, and who teaches at the local medical school. She recognised it instantly: I'd been "ICE'd."

In other words, she explained, the doctor had been looking for my Ideas, Concerns, and Expectations. She offered an example: a patient might think his symptoms are cancer when actually they are something much less serious, but he might not share that information without being asked; ICE is taught as a communications tool to help get at what patients are worrying about so doctors can deal with those concerns.

\section{The best intentions}

As you probably already know, she was right. I found websites that suggested doctors ask: "Tell me about what you think is causing it?" and "what were you hoping we might do for this?" I learnt that these come from good intentions; concerned doctors trying hard to look at the whole patient rather than to reduce their patients to a bunch of symptoms.

I wonder, though, did anyone ask patients how these questions sound or might make them feel?

When doctors ask me "what do you think is wrong?" it either sounds as if they don't know what they are doing or feels like they are testing me. It is as if they have gathered all the symptoms and know the answer but won't share it, in a game in which only the doctor knows the rules. This makes me feel less and less likely to trust that doctor.

There are some more worrying aspects too. For example, one GP training website goes on to suggest asking patients about their "darkest moments," or "what are your worst fears?" How can that possibly end well? In the darkest moments, what fears do I have about my health that we can deal with in the remaining two minutes of this consultation? However good doctors are, I doubt they will be able to address my worst fears in that time.

\section{Doing without ICE}

A little while later I saw a doctor who I felt had gold standard communication skills. Afterwards I thought about what she had done to make me feel so able to talk to her. Instead of probing my feelings with ICE-based questions, her primary focus was answering the questions I had asked, so I felt she was listening, and that we were working together. If she needed information I had not yet volunteered, she made clear why she was asking each question. She shared her thoughts as we went along, so we could discuss them, rather than putting me on the spot-and that made it much easier for me to share my thoughts and worries with her, too. It didn't take long. I had already started to trust her in the first 15 seconds.

I understand now why GPs ICE me. But an acronym can't build rapport; it's just another checklist. And it feels like it, on the receiving end.

\section{Competing interests: see http://tinyurl.com/hq3bvrw.}

Published by the BMJ Publishing Group Limited. For permission to use (where not already granted under a licence) please go to http://group.bmj.com/group/rights-licensing/ permissions 


\section{What you need to know}

Try to avoid using acronyms or formulaic questions to structure conversation with patients

Share and discuss your thoughts as you go along: knowing why you ask a question will help patients give a more useful answer

If you don't have time to cope with the reply, think carefully before asking patients to express their fears

Figure

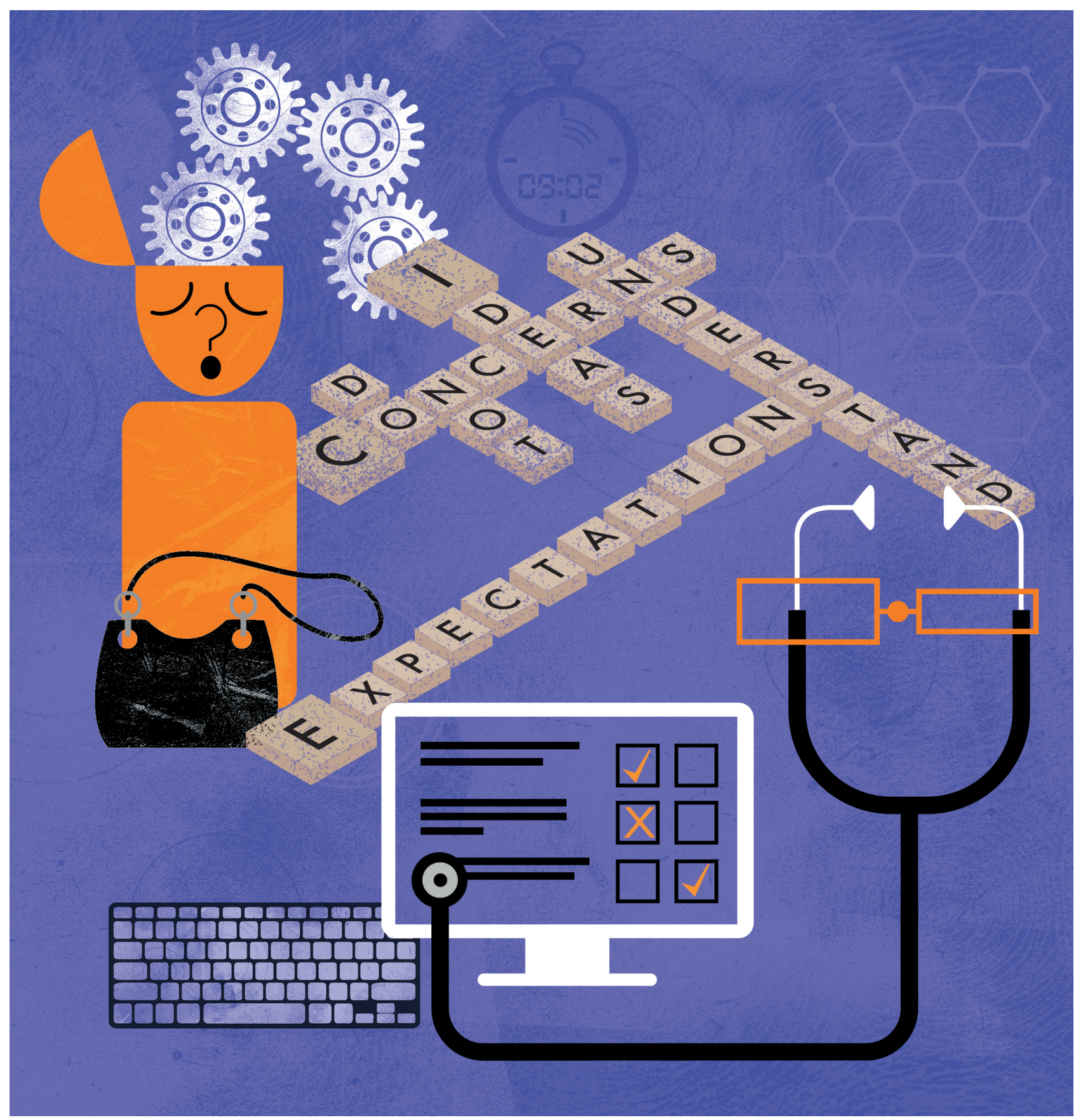

[Image: Rose Lloyd] 